with a resolution of the Congress of Universities of the Commonwealth in July 1948, lists postgraduate awards for advanced study and research tenable in the United Kingdom. Each award is differentiated in respect of eligibility for graduates of universities in the United Kingdom, graduates of British universities overseas, and graduates of universities outside the British Commonwealth. The awards are arranged by subject, and those open only to graduates of the university announcing it are not included. Appendix III lists similarly some of the more important postgraduate awards tenable overseas by British graduates, but does not claim to be exhaustive; it is intended primarily for United Kingdom graduates wishing to study abroad. The pamphlet is well printed and produced and constitutes a most convenient pocket reference work. Reference is made to other publications of similar type.

\section{Paris Academy of Sciences}

THE following elections have been made by the Paris Academy of Sciences: Prof. R. de Malleman, professor of physics in the University of Nancy, to be a non-resident member in succession to the late Dr. P. Teilhard de Chardin; Prof. G. Darmois, professor of mathematics in the University of Paris, to be member of the Astronomy Section in succession to the late Dr. J. Chazy ; Prof. E. Gäumann, professor of plant pathology in the Swiss Federal Institute of Technology, Zurich, and Prof. A. Blalock, professor of surgery in the Johns Hopkins University, Baltimore, to be foreign associates in succession to the late Prof. A. F. Blakeslee and the late Sir Alexander Fleming, respectively.

\section{Eighth Science Congress of the Royal Society of New Zealand}

The report of the Eighth Science Congress of the Royal Society of New Zealand, held at Auckland during May 17-21, 1954, has now been published as Part 4 of Vol. 82 of the Society's Transactions (pp. 150. Wellington: Royal Society of New Zealand, 1955). Besides the presidential address of Dr. W. B. B. Oliver, on "Changes in the Flora and Fauna of Now Zealand", it includes the addresses of the chairmen of the various sections, with the exception of Section $J$ (Anthropology), which is given only in abstract. Also published in the report are the two public lectures : that of Prof. M. L. E. Oliphant on "Science and Mankind", and that of Dr. R. N. Robertson on "The Struggle against Equilibrium-a Physico-Chemical Problem in Life". Prof. Oliphant's examination of the foundations of scientific activity, the part it now plays in any developed community and where it is likely to lead, is of very general interest ; and his comments on the use and misuse of knowledge, particularly with reference to nuclear physics, are highly pertinent to current discussions on nuclear weapons and nuclear power. A number of chairmen's addresses are also of general interest, notably Prof. E. Beaglehole's discussion of the study of social change in relation to the administra- tion of programmes of technical assistance, that of Dr. M. M. Burns on "Agricultural Science: Contributions and Challenges", and, to a lesser extent, Mr. J. I. King's discussion of the relative problems of the two professions of architecture and engineering. The contributions of Dr. H. O. Askew on biology and the trace elements, of Dr. R. C. Lister on rural settlement, with examples from Canterbury and Southland, and of Mr. N. H. Taylor on the role of soil science in New Zealand problems, are more specialized but still of some general interest, and are presented in a way which will appeal to the general public.

\section{Announcements}

DR. R. L. Smith-Rose, director of radio research in the Department of Scientific and Industrial Research, has been appointed acting director of the National Physical Laboratory, following the resignation of Sir Edward Bullard and pending the appointment of a new director.

Dr. Dexhev Bronk, O.B.E., For.Mem.R.S., president of the Rockefeller Institute and of the U.S. National Academy of Sciences, has been appointed chairman of the Board of the U.S. National Science Foundation.

Mr. K. J. B. Wolfe, formerly deputy director of research for the B.S.A. Company, Ltd., and chief metallurgist, B.S.A. Tools Group of Companies, has been appointed head of fundamental research by the Triplex Safety Glass Co., Ltd., and will take charge of the company's new research department to be built at its Willesden factory in West London.

The Cigar Manufacturers Association of America, in conjunction with the Cigar Institute of America, has made this year's Cigar Industry Annual Research Award to Dr. Walter G. Frankenburg, of Lancaster, Pennsylvania, in recognition of his outstanding contributions to the development of the basic science and technology of tobacco; in particular, for his investigations of the chemical processes that occur in the harvested tobacco leaf, including the conversion of nicotine into a series of other substances, and for the successful application of this new knowledge to problems of the cigar industry. The Award is open to persons engaged in research on the chemistry, biochemistry, biophysics, physiology or agronomy of cigar tobaccos. Consideration for the next Award will be given to all communications submitted to the Chairman, Industry Committee on Awards, Room 2214, 350 Fifth Avenue, New York 1, N.Y.

ERRATUM.-Referring to the article "Acceleration of Abscission by a Factor produced in Senescent Leaves", by Dr. Daphne J. Osborne (Nature, December 17, p. 1161), the author writes that in Table 1, the figure 55 in the second column from the left should be 65 . Moreover, a cursory glance at the table might lead the reader to suppose that all the data refer to one experiment rather than to four. To avoid this, the following table should be substituted:

Table 1. Average time in hours for abscission of bean explants when (a) agar blocks containing diffusates from young or abscinded pulvini are applied to the pulvinar end ; or $(b)$ whole pulvini are sealed with agar to the pulvinar end

\begin{tabular}{|c|c|c|c|c|c|c|c|}
\hline \multicolumn{4}{|c|}{$(a)$} & \multicolumn{4}{|c|}{ (b) } \\
\hline & Control & $\begin{array}{l}\text { Diffusate from } \\
\text { young pulvini }\end{array}$ & $\begin{array}{l}\text { Diffusate from } \\
\text { abscinded pulvini }\end{array}$ & & Control & $\begin{array}{l}\text { Pulvini from } \\
\text { attached leaves }\end{array}$ & $\begin{array}{l}\text { Pulvini from } \\
\text { abscinded leaves }\end{array}$ \\
\hline $\begin{array}{l}\text { Expt. } 1 \\
\text { Expt. } 2\end{array}$ & $\begin{array}{r}107 \\
61\end{array}$ & $\begin{array}{r}105 \\
65\end{array}$ & $\begin{array}{l}88 \\
53\end{array}$ & $\begin{array}{l}\text { Expt. } 3 \\
\text { Expt. } 4\end{array}$ & $\begin{array}{r}>120 \\
57\end{array}$ & $\begin{array}{l}55 \text { (from senescent leaves) } \\
56 \text { (from young leaves) }\end{array}$ & $\begin{array}{l}45 \\
37\end{array}$ \\
\hline
\end{tabular}

